\title{
Long term outcome of soybean epidemic asthma after an allergen reduction intervention
}

Josep M Antó, Joan B Soriano, Jordi Sunyer, María J Rodrigo, Ferran Morell, Josep Roca, Robert Rodríguez-Roisín, Mark C Swanson

Abstract

Background-Asthma outbreaks due to the inhalation of soybean dust released from handling of soybean in the city harbour occurred in Barcelona, Spain from 1981 to 1987 . The installation of bag filters in the responsible silo was followed by a substantial reduction of airborne soybean dust released into the atmosphere and the disappearance of asthma outbreaks. A study was undertaken to assess the relevant outcomes in asthma patients affected by soybean epidemic asthma eight years after this environmental intervention.

Methods-A repeat case-control study was performed in 1995 on a population of subjects with epidemic and non-epidemic asthma previously assessed in 1989. The same protocol was used in both surveys to collect data from patients via a questionnaire and respiratory function, skin and laboratory tests were performed under blinded conditions with regard to epidemic and non-epidemic status. Environmental soybean allergen in pollution filters was measured by means of a RAST inhibition technique.

Results-During 1995 and 1996 the 24 hour mean airborne levels of soybean allergen on a sample of 39 unloading days (range 31-269 $\mathrm{U} / \mathrm{m}^{3}$ ) were systematically below the lowest level ever detected during an epidemic day $\left(1500 \mathrm{U} / \mathrm{m}^{3}\right)$. Measurable levels of serum IgE antibodies against soybean were still present in $55 \%$ of patients with epidemic asthma compared with $6.0 \%$ of those with non-epidemic asthma $(p<0.05)$. These proportions were almost identical to those observed in 1989. The proportion of patients with soybean asthma with symptoms in 1989 who reported the absence of symptoms in 1995 was similar to the control subjects, so most of the relative risks (RRs) of improvement were near to 1 . The only statistically significant differences between the two groups were a smaller proportion of patients with epidemic asthma showing improvement in terms of being woken up by attacks of coughing (RR improvement $0.47 ; 95 \%$ CI 0.22 to 0.99 ) and the need for treatment at the emergency room (RR improvement 0.63 ; $95 \%$ CI 0.41 to 0.96 ).

Conclusions-Eight years after a large reduction in the levels of airborne soybean allergen half of the former soybean epidemic asthma patients were still sensi- tised to soybean. These results indicate an initial improvement in soybean epidemic asthma in the two years following the intervention with no further improvement in subsequent years.

(Thorax 1999;54:670-674)

Keywords: epidemic asthma; environmental asthma; soybean; intervention

Allergen avoidance is widely considered a first line measure in the treatment of allergic asthma. Randomised controlled trials have shown that measures to decrease domestic levels of mite allergens are followed by a statistically significant improvement in symptoms and bronchial responsiveness in both asthmatic children and adults sensitised to mite. ${ }^{1-6}$ Support for house dust mite avoidance measures is increased in the most recent review of the British Thoracic Society asthma guidelines, ${ }^{7}$ although it is recognised that further research into avoidance procedures and duration of action is needed. Because the longest follow up period in a clinical trial was one year, there is no evidence as to whether or not improvement of asthma continues or persists with a longer duration of allergen avoidance. The long term effect of avoidance has also been assessed in workers who develop occupational asthma caused by agents including isocyanates, colophony and plicatic acid, some of them involving an IgE mechanism. These studies have shown that asthma persists for years in about $50 \%$ of cases-and possibly indefinitely-after avoidance of exposure. $^{8}$

Soybean epidemic asthma has provided a useful model of environmental asthma ${ }^{9}$ which in some respects is comparable to occupational asthma. We previously reported the disappearance of asthma outbreaks and a striking reduction in the rates of admission to intensive care units for asthma during the two years following the installation of bag filters in a silo unloading soybeans in the harbour of Barcelona. ${ }^{10}$ Two years after the intervention, asthma in individuals affected during the soybean asthma outbreaks had a favourable prognosis with a significant reduction in the rate of $\mathrm{IgE}$ sensitisation to soybean and fewer symptoms than control subjects. ${ }^{11}$ To determine the long term changes in asthma after exposure to soybean dust a repeat case-control study was conducted eight years after the intervention. 


\section{Methods}

ENVIRONMENTAL MONITORING OF SOYBEAN ALLERGEN

All air samples were obtained at the same site located about $2000 \mathrm{~m}$ (1.3 miles) from the point source. A set of filters routinely collected by the air pollution monitoring network system was assayed for content of low molecular weight soybean allergen as 24 hour mean levels by a RAST inhibition method. ${ }^{12}$ Filters were collected and assayed in a blind fashion with regard to soybean unloading in the city harbour on that particular day. Assays were performed at the Allergic Diseases Research Laboratory of the Mayo Clinic (Rochester, Minnesota, USA). The results are given as units of low molecular weight (LMW) soybean allergen per cubic metre (1 U corresponding approximately to $1 \mathrm{ng}$ ). A schedule of unloading activities was provided by Barcelona harbour authorities.

\section{STUDY DESIGN}

A group of 316 adult patients admitted to the emergency services of four large hospitals in Barcelona because of an acute attack of asthma between 1981 and 1987 was identified and contacted in 1995. These individuals had attended either on days of epidemics of asthma due to soybean (epidemic asthma group, $\mathrm{n}=$ 169) or non-epidemic asthma days (nonepidemic group, $\mathrm{n}=147$ ) and were studied for the first time in 1989. The study design consisted of a repeat case-control study with the baseline study conducted in $1989^{11}$ and repeated in 1995.

In a previous study in which asthma was defined as current symptoms of asthma plus bronchial hyperresponsiveness and/or atopy, the positive predictive value of a diagnosis of asthma in the emergency rooms was $86.3 \%$ in patients with epidemic asthma (cases) and $91.9 \%$ in those with non-epidemic asthma (controls). ${ }^{13}$ Fieldwork was done from March to December 1995. Both fieldwork and laboratory analyses were performed blinded for the status of cases and controls. This study was approved by the institutional committees on ethical practice and all individuals gave informed written consent.

The study included the administration of a short version of the ATS-DLD78 standardised respiratory questionnaire ${ }^{14}$ with additional questions from the IUATLD questionnaire, ${ }^{15}$ measurement of total serum IgE concentrations and atopy, and assessment of bronchial responsiveness. Although the organisation of the questionnaire was different, the wording of the questions about symptoms considered in the present study was identical on the two occasions.

Total IgE levels were assessed by fluoroimmunoassay (CAP system, Pharmacia Diagnosis $A B$, Uppsala, Sweden) and values were expressed in $\mathrm{kU} / \mathrm{l}$ using an $\mathrm{IgE}$ standard calibrated against the reference preparation $75 / 502$ WHO human serum IgE. Specific serum IgE antibodies to soybean were assessed in 1989 using a RAST assay (Pharmacia Diagnosis AB, Barcelona, Spain) with $>0.35$ PRU/ $\mathrm{ml}$ being the threshold positive value. This technique is no longer available so the CAP method was used for samples collected in 1995 with an equivalent threshold positive value of $\geqslant 0.35 \mathrm{kU} / \mathrm{ml}$. Atopy was assessed by standard skin prick testing to common allergens including house dust, Dermatophagoides pteronyssinus, Dermatophagoides farinae, cat, dog, tree mix, graminaceae mix, weed mix, Aspergillus, and Alternaria (CBF LETI, Barcelona, Spain). A reaction was considered positive when a weal of $\geqslant 3 \mathrm{~mm}$ diameter to one or more allergens was observed in an individual with a positive histamine control and a negative saline control. Testing of skin soybean sensitivity was performed using a dry extract from the hull at a dilution of $1 / 10$ protein concentration $(100 \mu \mathrm{g} /$ ml) with $50 \%$ sterile glycerine. ${ }^{16}$

Bronchial responsiveness was assessed by means of a dose response methacholine challenge or a bronchodilator test according to the same protocol as in the 1989 original assessment. ${ }^{11}$ Methacholine was administered through a Hudson nebuliser. Individuals not eligible for a methacholine challenge (forced expiratory volume in one second $\left(\mathrm{FEV}_{1}\right)<70 \%$ predicted or $<1.5 \mathrm{l}$ ) performed a bronchodilator test with salbutamol. Bronchial responsiveness was defined as the dose provoking a fall in $\mathrm{FEV}_{1}$ of $20 \%$ or more $\left(\mathrm{PD}_{20}\right)$ of $\leqslant 8 \mathrm{mg}$ methacholine or $\geqslant 15 \%$ improvement in $\mathrm{FEV}_{1}$ after the bronchodilator test.

STATISTICAL ANALYSIS

Discrete data were analysed by the $\chi^{2}$ test with the Yates' correction if the value of a cell was lower than 5. For continuous measurements a two tailed $t$ test was used. The repeated case-control design is a cohort study so, to estimate changes in symptoms in 1995 in cases and controls relative to their baseline condition in 1989 , two measures are presented for each symptom: the relative risk (RR) of improvement among those reporting a given symptom in 1989 and the relative risk of worsening in those without a given symptom in 1989. An RR of worsening of $>1$ indicated that, among subjects without a given symptom in 1989, cases were more likely to report this symptom in 1995 than controls. Similarly, among the individuals reporting a given symptom in 1989 , an $\mathrm{RR}$ of improvement of $>1$ indicated that cases were more likely not to report this symptom in 1995 than controls. All symptoms referred to the 12 month period prior to the interview. Calculation of RRs was performed with SPSS-PC and with the EpiInfo statistical package (Centres for Disease Control and Prevention, Atlanta) using logistic regression and with the Cornfield method for the calculation of the $95 \%$ confidence intervals.

\section{Results}

Soybean allergen levels (table 1 ) in air filters collected during 1995-6 on soybean unloading days were consistently low, being below the detection limit on 10 days with the highest level being $268 \mathrm{U} / \mathrm{m}^{3}$, and were not significantly different from levels on non-unloading days $(p=$ 0.47). The levels on both unloading and 
Table 1 Mean concentrations of airborne soybean allergen $\left(U / m^{3}\right)^{\#}$ during 1987-96† on unloading and non-unloading days in the harbour in Barcelona

\begin{tabular}{lllllllll}
\hline & \multicolumn{3}{c}{ Unloading days } & & \multicolumn{3}{c}{ Non-unloading days } \\
\cline { 2 - 4 } \cline { 7 - 8 } Periodt & $n$ & Mean & Range & & $n$ & Mean & Range \\
\hline $1987^{\star}$ & 12 & 324 & $10-10.590$ & & 18 & 19 & $9-1055$ \\
$1988-9 \star$ & 22 & 25 & $5-65$ & & 84 & 18 & $7-420$ \\
$1995-6$ & 39 & 35.8 & nd-268 & & 16 & 22.6 & nd-186.6 \\
\hline
\end{tabular}

ॠData reported in a previous study. ${ }^{4}$

†Assays performed in different periods in the same laboratory (Allergic Diseases Research Laboratory, Mayo Clinic and Mayo Foundation, Rochester, Minnesota, USA) under similar conditions, with different pools of serum samples from patients with soybean epidemic asthma.

\#Units are RAST inhibition units.

nd $=$ non-detectable.

non-unloading days were similar to those recorded during the period 1988-9 after the installation of bag filters at the top of the responsible silo.

Of a total of 316 asthmatic patients surveyed in 1989,31 had died by 1995 (18 (10.6\%) with epidemic asthma and $13(8.8 \%)$ with non-

Table 2 Characteristics of subjects with epidemic and non-epidemic asthma in 1995 $(n=203)$

\begin{tabular}{lll}
\hline & $\begin{array}{l}\text { Epidemic asthma } \\
(n=104)\end{array}$ & $\begin{array}{l}\text { Non-epidemic asthma } \\
(n=99)\end{array}$ \\
\hline Mean (SD) age (years) & $61.6(15.2)^{\star}$ & $53.7(15.6)$ \\
Women (\%) & $51.3^{\star}$ & 76.1 \\
Atopy (\%)』 & 60.9 & 53.7 \\
Geometric mean total IgE (kU/1) & $106.2^{\star}$ & 59.8 \\
Mean (SD) FEV $(\%$ predicted) & $62.7(26.3)$ & $66.8(23.9)$ \\
Bronchial responsiveness (\%)† & 73.0 & 78.8 \\
Use of inhaled glucocorticoids (\%) & 65.4 & 65.7 \\
Tobacco & & 62.1 \\
$\quad$ Never smokers (\%) & 48.7 & 22.4 \\
$\quad$ Ex-smokers (\%) & 34.6 & 15.5 \\
$\quad$ Current smokers (\%) & 16.7 & 5.6 \\
Skin soybean sensitivity (\%) $\ddagger$ & $57.8^{\star}$ & 6.0 \\
Serum soybean specific IgE (\%) & $55.1^{\star}$ & \\
\hline
\end{tabular}

${ }^{\star} \mathrm{p}<0.05$ for comparison between epidemic and non-epidemic asthmatic subjects.

\Atopy defined as one or more positive skin prick tests to a panel of allergens including house dust, Dermatophagoides pteronyssinus, Dermatophagoides farinae, cat, dog, tree mix, graminaceae mix, weed mix, Aspergillus, and Alternaria.

$+92.3 \%$ and $94.6 \%$ epidemic and non-epidemic asthmatic subjects, respectively, positive to methacholine when performed and $48.3 \%$ and $50 \%$, respectively, positive to bronchodilator test. ¥Soybean sensitivity by prick to $1 / 10$ glycerinated solution of soybean.

Table 3 Changes between 1989 and 1995 in respiratory symptoms during the preceding 12 months in subjects with soybean epidemic and non-epidemic asthma (relative risk with $95 \%$ CI)

\begin{tabular}{|c|c|c|c|c|}
\hline Symptom & $\begin{array}{l}\text { Epidemic } \\
\text { subjects (\%) }\end{array}$ & $\begin{array}{l}\text { Non-epidemic } \\
\text { subjects (\%) }\end{array}$ & Relative risk crude & $\begin{array}{l}\text { Relative risk } \\
\text { adjustedt }\end{array}$ \\
\hline \multicolumn{5}{|l|}{ Wheeze } \\
\hline Improvement ${ }^{\star}$ & $15(20.2)$ & $15(19.5)$ & $1.04(0.55$ to 1.97$)$ & $1.01(0.53$ to 1.93$)$ \\
\hline Worsening ${ }^{\star}$ & $16(53.3)$ & $16(72.9)$ & $0.73(0.48$ to 1.12$)$ & $0.72(0.47$ to 1.10$)$ \\
\hline \multicolumn{5}{|c|}{ Attacks of shortness of breath } \\
\hline Improvement & $32(53.4)$ & $35(59.4)$ & $0.90(0.65$ to 1.23$)$ & $0.80(0.61$ to 1.05$)$ \\
\hline Worsening & $9(20.6)$ & 7 (17.6) & $1.17(0.48$ to 2.85$)$ & $1.51(0.63$ to 3.59$)$ \\
\hline \multicolumn{5}{|c|}{ Tightness in the chest } \\
\hline Improvement & $20(49.9)$ & $32(60.3)$ & $0.83(0.57$ to 1.21$)$ & $0.73(0.49$ to 1.06$)$ \\
\hline Worsening & $17(26.5)$ & $14(30.3)$ & $0.87(0.48$ to 1.59$)$ & $0.91(0.48$ to 1.71$)$ \\
\hline \multicolumn{5}{|c|}{ Woken up by attacks of cough } \\
\hline Improvement & $8(23.5)$ & $13(37.0)$ & $0.63(0.30$ to 1.33$)$ & $0.47(0.22$ to 0.99$)$ \\
\hline Worsening & $20(28.5)$ & $16(25.0)$ & $1.14(0.65$ to 2.00$)$ & $1.12(0.64$ to 1.95$)$ \\
\hline \multicolumn{5}{|c|}{ Woken up by shortness of breath } \\
\hline Improvement & $28(59.5)$ & $22(45.8)$ & $1.30(0.88$ to 1.91$)$ & $1.25(0.87$ to 1.84$)$ \\
\hline Worsening & $12(21.0)$ & $9(17.7)$ & $1.19(0.55$ to 2.59$)$ & $1.38(0.63$ to 3.06$)$ \\
\hline \multicolumn{5}{|l|}{ Attack of asthma } \\
\hline Improvement & $24(57.2)$ & $30(61.2)$ & $0.93(0.66$ to 1.32$)$ & $0.88(0.64$ to 1.21$)$ \\
\hline Worsening & $24(38.7)$ & $13(25.9)$ & $1.49(0.85$ to 2.61$)$ & $1.65(0.93$ to 2.93$)$ \\
\hline \multicolumn{5}{|c|}{ Emergency room visits by asthma } \\
\hline Improvement & $12(52)$ & $28(80)$ & $0.65(0.42$ to 0.99$)$ & $0.63(0.41$ to 0.96$)$ \\
\hline Worsening & $16(19.8)$ & $8(12.5)$ & $1.58(0.72$ to 3.46$)$ & $1.60(0.71$ to 3.61$)$ \\
\hline
\end{tabular}

^Subjects showing "improvement" are those who answered "yes" to a symptom question in 1989 and answered "no" in 1995. Subjects showing "worsening" answered "no" in 1989 and "yes" in 1995.

†Adjusted by sex, age, and smoking. epidemic asthma) and 29 had moved to another geographical area $(12(7.1 \%)$ with epidemic asthma and $17(11.5 \%)$ with nonepidemic asthma). One subject with epidemic asthma and two controls died from asthma. A total of $203(79 \%)$ of the 256 eligible individuals were studied; there were no statistical differences in participation rates between epidemic and non-epidemic asthmatic subjects $(\mathrm{p}=0.28)$. The characteristics of both groups in 1995 are shown in table 2 . The subjects with epidemic asthma were older and there were fewer women $(p<0.05)$. No differences were observed in current smoking status, the percentage predicted basal $\mathrm{FEV}_{1}$, bronchial responsiveness, or use of inhaled steroids. Since a close similarity between both groups was also observed in $1989,{ }^{11}$ no further analysis on lung function and bronchial responsiveness was carried out. Epidemic asthma patients showed a trend to be more atopic with a higher geometric mean total $\operatorname{IgE}(\mathrm{p}<0.05)$, although skin reactivity to common aeroallergens was similar (sensitisation to at least one allergen $60.9 \%$ versus $53.7 \%, \mathrm{p}=0.43$ ).

A similar proportion of subjects with soybean asthma who reported symptoms in 1989 and controls reported the absence of symptoms in 1995 so, for most symptoms, the relative risks (RRs) of improvement were near to 1 (table 3). The only statistically significant differences were for being woken up by attacks of coughing (RR improvement $0.47 ; 95 \%$ CI 0.22 to 0.99 ) and for visits to the emergency room (RR improvement $0.63 ; 95 \%$ CI 0.41 to $0.96)$. Accordingly, when subjects not reporting a given symptom in 1989 were considered, soybean asthma subjects were slightly more likely to report the symptom in 1995 but none of the relative risks for worsening achieved statistical significance (table 3).

Because of limited availability of serum samples a paired comparison of changes in sensitisation to soybean between 1995 (kU/l; CAP technique) and 1989 (U/ml; RAST technique) was only possible in 52 subjects with soybean asthma and 52 controls. Of the patients with soybean asthma 23 had measurable levels of soybean $\operatorname{IgE}(\geqslant 0.35$, both $\mathrm{U} / \mathrm{ml}$ and $\mathrm{kU} / \mathrm{l})$ on both occasions while 27 did not. Only one reverted and one converted. Of the 52 controls 48 were negative on both occasions, one was positive, two converted, and one reverted.

\section{Discussion}

In a previous study we found that, two years after an intervention which eliminated the occurrence of outbreaks of soybean asthma, about $50 \%$ of subjects affected by the outbreaks showed measurable levels of specific IgE to soybean compared with $74 \%$ before the intervention, ${ }^{10}$ subjects with epidemic asthma having fewer asthma symptoms than controls. ${ }^{11}$ In the present study, eight years after the intervention, symptoms of asthma were more likely to improve than to worsen in both study groups but subjects with epidemic asthma were less likely to improve than controls, the latter being statistically significant only for being woken up by coughing and for visits to an emergency 
room. Of those with epidemic asthma, 55\% were still sensitised to soybean whereas lung function and bronchial responsiveness to methacholine were similar in both groups in 1989 and in 1995. These results strongly suggest an initial improvement in epidemic asthma in the two years following the intervention with no further improvement in subsequent years. It should be emphasised that the findings refer to individual outcomes and are in contrast to previously reported evidence of a dramatic improvement in the occurrence of asthma outbreaks. ${ }^{10}$

A clear cut interpretation of these results is limited since no information was available on the status of asthma prior to the occurrence of the outbreaks in the period 1980-7. However, an interpretation by analogy to both allergen avoidance trials and occupational asthma is possible. The results obtained in the present study appear to contrast with the view that avoidance of mite allergen is effective in improving asthma morbidity, ${ }^{7}$ but are in agreement with occupational studies in which asthma has been reported to persist in a substantial proportion of cases for years-and possibly indefinitely - after avoidance of exposure to causative agents.

Evidence for the efficacy of allergen avoidance in improving asthma symptoms has been mainly provided by randomised controlled trials of mite allergen avoidance in both children and adults with asthma and sensitisation to house dust mite. Studies in adults have shown statistically significant improvements in symptoms and/or bronchial responsiveness. ${ }^{1-3}$ One study showed no effect, probably because there was an insufficient reduction in the level of mite allergen. ${ }^{4}$ Randomised controlled trials of mite allergen avoidance in asthmatic children have shown either positive effects ${ }^{5}$ or no effects at all. ${ }^{11}{ }^{18}$ The different results from these studies may be due to the different type of interventions since bed covers have been found useful in the short term but the efficacy of acaricides remains unproven. ${ }^{7}$ The evidence for the persistence of occupational asthma after avoidance of the causative factors includes persistence of specific IgE to tetrachlorophthalic anhydride (TCPA), ${ }^{19}$ persistence of symptoms in patients with Western red cedar asthma, ${ }^{20}$ and in those with asthma due to isocyanates. ${ }^{22}$ Persistent asthma after avoidance of the responsible factors has also been reported for allergy to trimetillic acid (TMA), ${ }^{23}$ wasp venom, ${ }^{24}$ and platinum salts. ${ }^{25}$

In contrast to both mite allergen avoidance and occupational asthma, our study involved a population exposed to an airborne allergen in the community and we cannot exclude the presence of high levels of allergen on a few sporadic days as a relevant factor. During the study period we are aware of at least one such day on 29 October $1994 .^{26}$ The finding in the present study that, among those who reported a visit to an emergency room in 1989, controls were more likely not to report it in 1995 than were epidemic subjects may reflect the occasional exposure to unmeasured high levels of soybean allergen on sporadic days. These uncontrolled exposures to high levels of allergen may also be important in clinical trials of allergen avoidance in which the levels of allergen are measured on a few occasions during the study period and do not include measurement of exposures at work, school, or public places. The persistence of sensitisation and asthma symptoms in subjects with soybean asthma may also have resulted from continuous exposure to low levels of allergen over a long period of time. One possible explanation for the parallelism between our results and those obtained in occupational studies may be the longer follow up compared with trials on mite allergen. In contrast, the persistent exposure to low levels of allergen and the possible occurrence of sporadic exposures to high levels of allergen in our population is unlikely in some types of occupational asthma in which the causative molecules are absent in the nonoccupational environment.

Other potential explanations for the persistence of asthma after avoidance or reduction to allergen exposure, such as the retention of antigen in lung tissue as mentioned by Venables $e t a l^{19}$ or the presence of IgE autoantibodies to lung tissues, ${ }^{27}$ cannot be excluded. Saetta et al studied bronchial biopsy specimens of 10 subjects with occupational asthma to isocyanates at diagnosis and six and 21 months after cessation of exposure and found a significant decrease in both bronchial responsiveness to isocyanates and thickness of subepithelial fibrosis, but no change in non-specific bronchial responsiveness or in the number of macrophages and eosinophils. ${ }^{28}$ Unfortunately, no data were available in our study to consider any of these possibilities.

In interpreting our study results some methodological limitations need to be considered. Because controls were subjects who visited the emergency room for asthma but who had never been treated on an epidemic day, misclassification was unlikely. Misclassification may, however, have occurred with cases. Taking into account both the distribution of the expected number of visits on an epidemic day ${ }^{29}$ and the sampling scheme of soybean asthma cases in this study, we estimate that about 20 of the 213 cases may have been misclassified. The consequence of this misclassification pattern, if any, would have been a slight attenuation of the differences observed in our study. Assessment of sampling variation in relative risks for symptoms involved the calculation of a large number of confidence intervals, and the levels of significance achieved for being woken up by coughing and treatment in the emergency room should be taken with caution. On the other hand, the size of the study population was small and, although most of the relative risks for worsening indicated that worsening was more likely in subjects with soybean asthma than in controls, their confidence intervals were wide.

Another complicating factor is that in Barcelona several hundred asthmatics are still at risk of having severe attacks of asthma if sporadic releases of dust occur during soybean unloading operations at the city harbour. After the 
study period, on 12 June 1996, a peak of soybean allergen of $5032 \mathrm{U} / \mathrm{m}^{3}$ was recorded and considered responsible for 27 asthma visits to emergency departments, and possibly one death. Soybean epidemic asthma has been well documented in New Orleans, USA, ${ }^{30}$ Naples, Italy, ${ }^{31}$ Cartagena, Spain, ${ }^{32}$ and Tarragona, Spain. ${ }^{33}$ In all these areas subjects who have had soybean epidemic asthma may be at risk of severe asthma attacks which may eventually be fatal in the case of re-exposure. In order to keep the levels of airborne soybean allergen in these areas as low as possible, the use of highly efficient control measures of emissions may be necessary. Since the outbreak which occurred in 1996, the soybean industries and the harbour authorities in Barcelona have established improved filtering measures to achieve additional reduction of soybean dust emissions and a monitoring system of airborne soybean allergen is being operated by the City Council.

The finding that, in subjects previously affected by soybean epidemic asthma, this condition persisted during a long period despite a considerable reduction in exposure to soybean dust, highlights the importance of primary prevention. Because soybeans are traded worldwide the use of effective technology to control the emission of soybean allergenic particles from soybean industries may be necessary in other places with populations living in their vicinity.

This study was supported by Fondo de Investigación Sanitaria (FIS 95/0050-01) and by Generalitat de Catalunya (CIRIT/ 997 SGR 00079). The authors thank Lourdes Ricart for her technical collaboration, Dolors Carrascal and Jordi Vila fo reporting the unloading activities in the harbour of Barcelona, Helena Martínez and Eduardo Pidal for secretarial assistance, Dr Marta Pulido for editorial assistance, Professor Charles E Reed for recommendations on airborne allergen measurements and, most specially, all patients who participated in the study.

1 Huss K, Aquire EN, Carpenter GB, et al. Effective education of adults with asthma who are allergic to dust mites. $\mathscr{F}$ Allergy Clin Immunol 1992;89:836-43.

2 van der Heide S, Kauffmann HF, Dubois AEJ, et al. Allergen reduction measures in houses of allergic asthmatic patients: effects of air-cleaners and allergen-impermeable mattress covers. Eur Respir F 1997;10:1217-23.

3 Dorward AJ, Collof MJ, MacKay NS, et al. Effect of house dust mite avoidance measures on adult atopic asthma. Thodust mite avoidance $\mathrm{r}$

4 Marks GB, Tovey ER, Green W, et al. House dust mite allergen avoidance: a randomized controlled trial of surface chemical treatment and encasement of bedding. Clin Exp Allergy 1994;24:1078-83.

5 Burr ML, Neale E, Dean BV, et al. Effect of a change to mite-free bedding on children with mite-sensitive asthma: controlled trial. Thorax 1980;35:513-4.

6 Ehnert B, Lau-Schadendorf S, Weber A, et al. Reducing domestic exposure to dust mite allergen reduces bronchia hyperreactivity in sensitive children with asthma. F Allergy Clin Immunol 1992;90:135-8.

7 British Thoracic Society, et al. The British guidelines on asthma management: 1995 review and position statement. Thorax 1997;52(Suppl 1):S1-21.

8 Newman Taylor AJ. Occupational asthma. Postgrad Med $\mathcal{F}$ 1988;64:505-10.
9 Antó, JM, Sunyer J, Newman-Taylor AJ. Comparison of soybean epidemic asthma and occupational asthma. Thorax 1996;51:743-9.

10 Antó JM, Sunyer J, Reed CE, et al. Preventing asthma epidemics due to soybeans by dust-control measures. $N$ Engl f Med 1993;329:1760-3.

11 Sabrià J, Antó JM, Sunyer J, et al. Clinical and functional characteristics of patients two years after being affected by the soybean asthma epidemic in Barcelona. Thorax 1994;49:906-9.

12 Swanson MC, Li JT, Wentz-Murtha PE, et al. Source of the aeroallergen of soybean dust: a low molecular mass glycopeptide from the soybean tela. $\mathcal{F}$ Allergy Clin Immunol 1991;87:783-8.

13 Sabrià J. Estudi clínic-epidemiològic de l'asma epidèmica per soja i validació del diagnòstic d'asma en els serveis d'urgències hospitalaries. Doctoral Thesis. Universitat Autònoma de Barcelona, Barcelona, 1992: 150

14 Ferris BG. Epidemiology standardization project II. Recommended respiratory disease questionnaire for use with adults and children in epidemiologic research. Am Rev Respir Dis 1978;118(Suppl):7-53.

15 Burney PGJ, Chinn S. Developing a new questionnaire for measuring the prevalence and distribution of asthma. Chest 1987;91(Suppl 6):79-83s.

16 Morell F, Codina R, Rodrigo MJ, et al. Clinical aspects of allergic disease. Diagnosis of soybean-induced asthma. $\mathcal{F}$ Allergy Clin Immunol 1995;96:320-4.

17 Frederick JM, Warner JO, Jessop WJ, et al. Effect of a bed covering system in children with asthma and house dust mite hypersensitivity. Eur Respir f 1997;10:361-6.

18 Warner JA, Marchant JL, Warner JO. Double blind trial of ionisers in children with asthma sensitive to the house dust mite. Thorax 1993;48:330-3.

19 Venables KM, Topping MD, Nunn AJ, et al. Immunologic and functional consequences of chemical (tetrachlorophthalic anhydride)-induced asthma after four years of avoidance of exposure. F Allergy Clin Immunol 1987;80:212-8.

20 Chan-Yeung M, Lam S, Koener S. Clinical features and natural history of occupational asthma due to western red cedar (Thuja plicata). Am F Med 1982;72:411-5.

21 Chan-Yeung M. Immunologic and nonimmunologic mechanisms in asthma due to western red cedar (Thuja plicata). F Allergy Clin Immunol 1982;70:32-7.

22 Lozewicz S, Assoufi BK, Hawkins R, et al. Outcome of asthma induced by isocyanates. Brf Dis Chest 1987;81:1422.

23 Zeiss CR, Patterson R, Pruzansky JJ, et al. Trimetillic anhydride-induced airway syndromes: clinical and immunological studies. F Allergy Clin Immunol 1977;60:96.

24 Aalberse RC. The IgE response and atopy. Eur Respir $\mathcal{f}$ 1991;4(Suppl 13):78-84s.

25 Merget R, Reineke M, Rueckmann A, et al. Nonspecific and specific bronchial responsiveness in occupational asthma caused by platinum salts after allergen avoidance. $A m \mathcal{F}$ Respir Crit Care Med 1994;150:1146-9.

26 Soriano JB, Antó JM, Plasència A, and the Barcelona Soybean-Asthma Group. Repeaters count: a sentinel method for asthma outbreaks. Thorax 1995;50:1101-3.

27 Nawata Y, Koike T, Yanagisawa T, et al. Anti-IgE autoantibody in patients with bronchial asthma. Clin Exp Immunol $1984: 58: 348$.

28 Saetta M, Maestrelli P, Turato G, et al. Airway wall remodeling after cessation of exposure to isocyanates in sensitized asthmatic subjects. Am $\mathcal{F}$ Respir Crit Care Med 1995;151: 489-94

29 Antó JM, Sunyer J. Soya bean as a risk factor for epidemic asthma. In: Elliott P, Cuzick J, English D, Stern R, eds. Geographical and environmental epidemiology methods for small area studies. Oxford: Oxford University Press, 1992. 323-41.

30 White MC, Etzel RA, Olson DR, et al. Reexamination of epidemic asthma in New Orleans, Louisiana, in relation to the presence of soy at the harbor. Am f Epidemiol 1997;145: $1-7$.

31 Cocco G, Schiano M, Sacerdoti G, et al. Functional characteristics in soybean asthma. Am f Respir Crit Care Med 1995;152:469.

32 Navarro C, Márquez M, Hernando L, et al. Epidemic asthma in Cartagena, Spain, and its association with soybean sensitivity. Epidemiology 1993;4:76-9.

33 García-Ortega P, Rovira E, Mora E. Epidemias de asma alérgica a semilla de soja en ciudades pequeñas. Med Clin (Barc) 1997;108:677. 